\title{
Utility Of Frozen Section Versus IOPTH In Parathyroid Surgery
}

\author{
Shiva Prasad ${ }^{1}$, Padmapriya Jaiprakash ${ }^{2 *}$ \\ 'Manipal Academy of Higher Education, Karnataka - 576104, India \\ ${ }^{2}$ Manipal Academy of Higher Education, Karnataka - 576104, India
}

\begin{abstract}
Introduction: Parathyroid surgeries are becoming less extensive procedures, with reduced hospital stay. The use of intraoperative frozen section help the surgeon in identifying the pathology, thereby determining the nature of surgery.

Aim: To study the utility of frozen section in comparison to chemical frozen section in our set up

Materials and Methods: Data was collected from records of department of Pathology during a period of 3 years. Only those cases were included in which the patient had undergone parathyroidectomy, with specimen being sent for frozen section and intra-operative parathyroid hormone (IOPTH) simultaneously.
\end{abstract}

Results: Frozen section diagnosis was concordant in 11/15 (73\%) cases. Significant percentage drop in IOPTH was seen in $13 / 15(86 \%)$ cases. We found frozen section useful in identifying parathyroid when there were multiple neck swellings.

Conclusion: The utility of frozen section in parathyroid surgery is diminishing and it is being replaced by better and more accurate biochemical assays.

Keywords: Frozen, Parathyroid, Chemical

\section{Introduction}

With the widespread use of radioactive technetium-99m sestamibi scan, the localization of parathyroid has become accurate. This has led to an increase in minimally invasive surgical procedures with smaller surgical incisions. ${ }^{[1]}$ As the half-life of parathyroid hormone $(\mathrm{PTH})$ is very short (2-5 minutes), taking the preoperative PTH levels as the baseline, rapid intra-operative parathyroid hormone (IOPTH), also called the chemical frozen section, sent 5-10 minutes after the removal of the enlarged gland provides an excellent method to assess the completion of the surgery. ${ }^{[2]}$

A fall of $>50 \%$ in the PTH levels indicates successful removal of the hormone producing tumor. Thus, in the era of 'chemical frozen section', the 'original' frozen section is essential in certain specific situations, like when the drop in PTH is not as expected, or when there are multiple nodules, either parathyroid or the adjacent thyroid or even lymph nodes or the thymus. It is also indicated in cases of an infiltrating neck mass where parathyroid carcinoma is suspected or in cases with extreme hypercalcemia. ${ }^{[2]}$

\section{Materials and Methods}

This was a retrospective study, conducted in a tertiary care center in South India during the period of January 2015 to December 2017. This study was performed in accordance with the principles of the Declaration of Helsinki. Data was retrieved from the records in the department of Pathology and the digital records in Laboratory Information System (LIS). Patient details were coded, and direct and indirect identifiers were avoided. The data of specimens of parathyroid tissue sent for frozen section were identified. Then LIS was used to identify those cases which had an IOPTH sent around the same time (+/-10 minutes) as the frozen section. Parathormone (PTH) was assessed by chemilumiscence method. The gold standard for final diagnosis was histopathology following paraffin embedding along with fall in the parathormone levels.

Inclusion criteria: Parathyroidectomies which had both frozen section (FS) and IOPTH

Exclusion criteria: Parathyroidectomies having only FS and those with neither FS nor IOPTH

The imprint smears, frozen sections and histopathology slides were retrieved and reviewed. Imprint smears and frozen sections were stained by rapid haematoxylin and eosin (H\&E). The results were tabulated and analyzed.

\section{Results}

A total of 672 cases were received for frozen section, by the department of Pathology during the period between January 2015 and December 2017. Of these, the parathyroid tissue 
received were 24 cases. A total of 15 cases which satisfied the inclusion criteria were included in our study group.

There were 13 cases of parathyroid adenomas (PTA), including one intrathyroid adenoma and chief cell adenoma. One case each of atypical PTA and parathyroid carcinoma was present. The mean age of presentation was 41.8 years (with a range of 18-62 years). Females were involved more than the males (F:M ratio-1.5:1). All the cases had elevated parathyroid hormone levels, preoperatively, with a range of 73.6 to $1397 \mathrm{pg} / \mathrm{mL}$. The percentage drop in the IOPTH ranged between 42.5 and 97.9 . The results have been summarized in table 1 . Taking $50 \%$ as cut off, only 2 cases were below the range $(13.3 \%)$. The sensitivity of IOPTH is definitely more when compared to the frozen section $(87 \%$ versus $73 \%$ ) in our series.

Imprint smears showed cellular smears with sheets and occasional rosettes of cells with fragile cytoplasm, vesicular nucleus with powdery chromatin and inconspicuous nucleoli (figure 1). Frozen sections showed cellular lesion composed of sheets of clear or oxyphil cells, devoid of adipocytes, which are seen in normal parathyroid (figure 2).

Frozen section diagnosis was concordant in 11 cases (73.33\%). One case diagnosed as PTA showed capsular invasion in the paraffin section and was diagnosed as carcinoma. In two cases, diagnosis was deferred, and it was termed as (cellular) parathyroid tissue identified. In one case, a doubt was expressed whether it was parathyroid neoplasm. The average time for a frozen section diagnosis was 20-25 minutes, while the time taken for IOPTH was 15 minutes. Taking a cut-off of $50 \%$ fall in IOPTH, only two cases fell out of the range. In 12 cases, only one specimen was sent for frozen. However, more than one specimens were received in 3 cases.

In case 1 , the first specimen was diagnosed as PTA on frozen. Though the fall in IOPTH was not seen, the surgeon decided to close. However, as both post-operative PTH and Calcium $\left(\mathrm{Ca}^{2+}\right)$ levels were high, re-exploration was done after a couple of weeks. As the histopathology was reported as hyperplasia, other two and a half glands were removed. Ultimately, a nodule which was suspected to be thyroid gland was removed and IOPTH showed significant drop of $97 \%$.

Case 5 similarly had 4 specimens sent for frozen including lymph nodal mass, diagnosed as tuberculous lymphadenitis, thymus gland, a normal parathyroid gland and PTA. In case 14, the first excised nodule was an adenomatoid goiter in thyroid. The specimen sent following this nodule was much smaller in size. However, it turned out to be the enlarged parathyroid gland, as excision was followed by a drop in the IOPTH.

Table: showing clinical, pathological and biochemical parameters studied.

\begin{tabular}{|c|c|c|c|c|c|c|c|c|c|c|c|}
\hline SI no & $\begin{array}{l}\text { Age/ } \\
\text { sex }\end{array}$ & Sex & $\begin{array}{l}\text { Pre-op PTH } \\
\text { (pg/mL) }\end{array}$ & $\begin{array}{l}\text { Intra-op PTH } \\
\text { (pg/mL) }\end{array}$ & $\begin{array}{l}\text { \%age } \\
\text { drop }\end{array}$ & $\begin{array}{l}\text { Specimens } \\
\text { received }\end{array}$ & Frozen diagnosis & Size (in cms) & $\begin{array}{l}\text { Weight (in } \\
\text { grams) }\end{array}$ & HPE & $\begin{array}{l}\text { Follow up } \mathrm{Ca2+} \\
\text { (mg/dL) }\end{array}$ \\
\hline 1 & 29 & M & 409.7 & 8.5 & 97.9 & 4 & PTA & $5 \times 2.5 \times 1$ & 11 & PTA & 10.0 (1 month) \\
\hline 2 & 52 & $F$ & 78.5 & 9.8 & 87.5 & 1 & PTA & $1.2 \times 0.8 \times 0.3$ & 1 & PTA & 9.6 (15 days) \\
\hline 3 & 59 & $M$ & 604.4 & 88.3 & 85.3 & 1 & Atypical PTA & $1 \times 0.8 \times 0.5$ & 2 & Atypical PTA & 8.9 (7 months) \\
\hline 4 & 50 & $F$ & 133.4 & 26.0 & 80.5 & 1 & PTA & $3.5 \times 2.5 \times 1$ & 3 & $\begin{array}{l}\text { Parathyroid } \\
\text { Carcinoma }\end{array}$ & $\begin{array}{l}10.4 \\
\text { (PTH } 43.4 \mathrm{pg} / \mathrm{mL} \text { ) } \\
\text { ( } 2 \frac{1}{2} \text { months) }\end{array}$ \\
\hline 5 & 41 & $F$ & 165.9 & 13.9 & 91.6 & 4 & PTA & $1 \times 0.8 \times 0.5$ & $<1$ & PTA & 8.9 (4 months) \\
\hline 6 & 46 & $F$ & 220.1 & 20.5 & 90.6 & 1 & PTA/ Malignancy & $2.5 \times 1.5$ & 2 & PTA & 9.8 (2 months) \\
\hline 7 & 26 & M & 120.7 & 69.4 & 42.5 & 1 & PTA & $1.5 \times 1$ & $<1$ & $\begin{array}{l}\text { PTA (oxyphiic } \\
\text { variant) } \\
\end{array}$ & $\begin{array}{l}83.3(\mathrm{PTH}) \\
(15 \text { days }) \\
\end{array}$ \\
\hline 8 & 44 & M & 300.8 & 74.1 & 75.3 & 1 & PTA & $1.5 \times 1.5 \times 1$ & 2 & PTA & 8.9 (1 month) \\
\hline 9 & 18 & $M$ & 224.7 & 16.5 & 92.7 & 1 & $\begin{array}{l}\text { Cellular parathyroid } \\
\text { tissue }\end{array}$ & $1.5 \times 1.4$ & $<1$ & Chief cell PTA & 8.1 (4 months) \\
\hline 10 & 62 & $\mathrm{~F}$ & 1397 & 264.3 & 81.1 & 1 & PTA & $2.8 \times 1.5 \times 1$ & 6 & PTA & 9.9 (5 months) \\
\hline 11 & 40 & $F$ & 133.3 & 9.3 & 93 & 1 & PTA & $3 \times 1.9 \times 1$ & 4 & PTA & 9.1(5 months) \\
\hline 12 & 45 & $F$ & 73.6 & 37.3 & 49.3 & 1 & PTA & $2 \times 1.2 \times 0.4$ & $<1$ & PTA & 9.0 (13 months) \\
\hline 13 & 34 & $F$ & 119.6 & 43.2 & 67.3 & 1 & PT neoplasm & $1.8 \times 0.8 \times 0.5$ & 3 & PTA & 9.7 (2 months) \\
\hline 14 & 26 & M & 184.9 & 21.9 & 88.2 & 2 & $\begin{array}{l}\text { Parathyroid identified } \\
\text { ? adenoma }\end{array}$ & $1.8 \times 1$ & 2 & PTA & 9.9 (1 month) \\
\hline 15 & 55 & $F$ & 284.8 & 78.2 & 72.5 & PTA & Parathyroid & $2.2 \times 1.5$ & $\mid<1$ & Intrathyroid PTA & 9.6 (6 months) \\
\hline
\end{tabular}

(Parathyroid adenoma - PTA) 


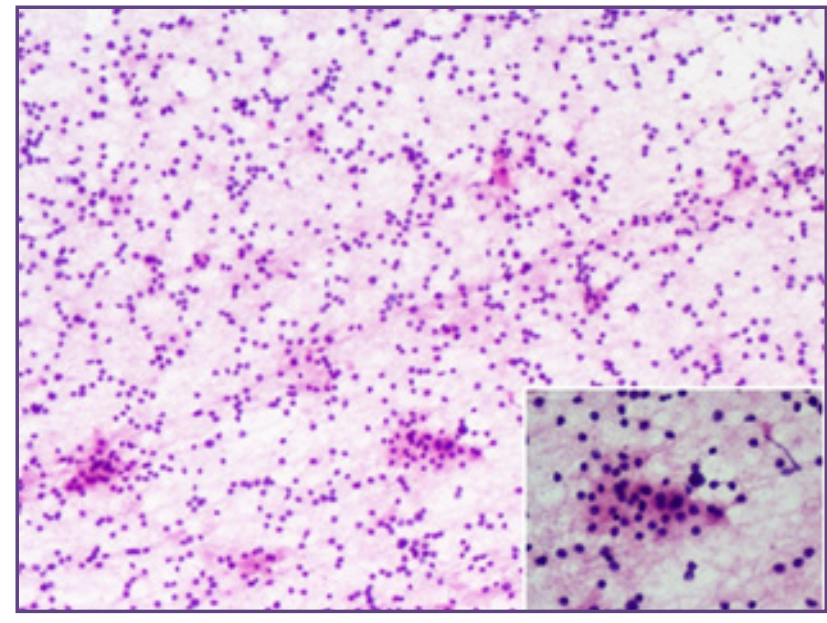

Fig. 1: Cellular imprint smears showing sheets of round cells with salt and pepper chromatin and scant fragile cytoplasm. (Rapid H\&E, 10x, inset 40x).

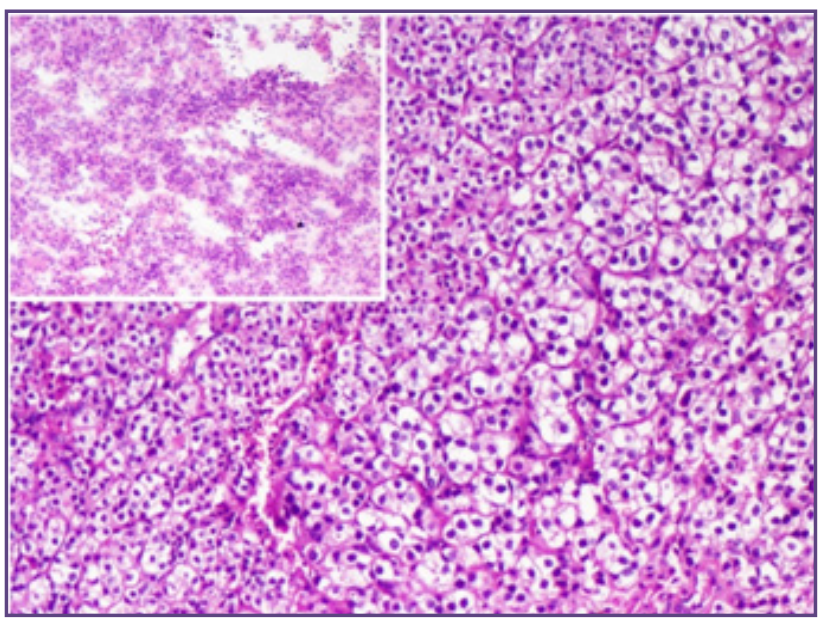

Fig. 2: Sheets of tumour cells with round nuclei, moderate clear cytoplasm with loss of fat spaces in between (H\&E, 10x). Inset - Frozen section showing the same (Rapid $\mathrm{H} \& \mathrm{E}, 10 \mathrm{x}$ ).

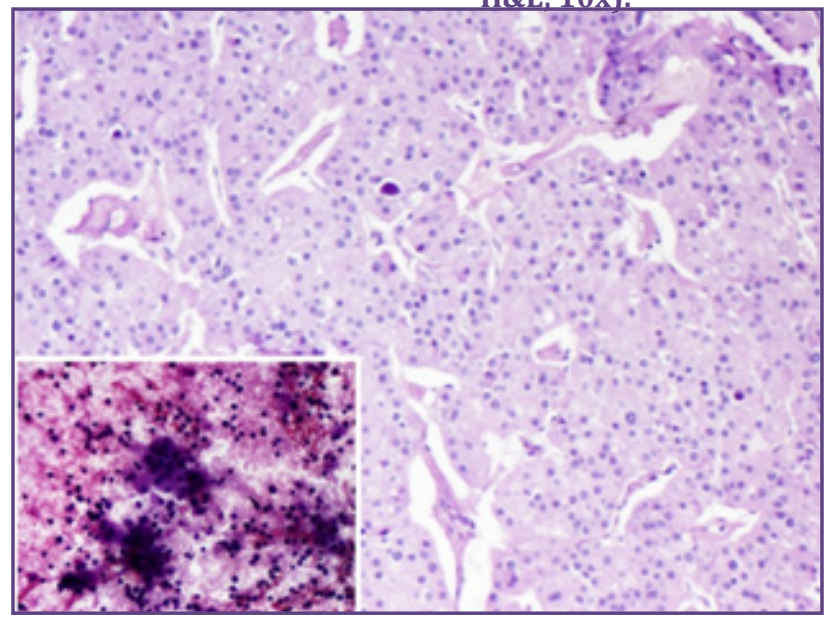

Fig. 3: Sheets of oncocytic cells with abundant granular eosinophilic cytoplasm, vesicular nucleus with interspersed capillaries (H\&E, 10x). Inset - Imprint smears with oncocytic cells (Rapid H\&E, 10x).

\section{Discussion}

The most common cause of primary hyperparathyroidism (PHP) is parathyroid adenomas followed by hyperplasia. Traditional bilateral neck dissection with exploration of all 4 parathyroid glands has now been replaced by single gland surgery and more recently, minimally invasive parathyroidectomy (MIP). [3] The role of frozen section has been questioned in recent times especially after the pre-operative localization of the parathyroid has been made possible by Technetium Tc $99 \mathrm{~m}$ sestamibi scans. ${ }^{[1]}$ Though the sensitivity ranges from $62-90 \%$ for solitary adenomas ${ }^{[1]}$, technical enhancement of sestamibi scanning has led to a decrease in the false negativity and increased localization. ${ }^{[4]}$
Some of the reasons hypothesized for the false negativity include smaller size and weight of the adenoma. Mehta et al found that the interpretation was more difficult when the size was less than $2 \mathrm{cms}$. They also found a correlation between number of oxyphil cells in the tumour and positivity. Thus they concluded that presence of predominantly chief cells was associated with greater PTH secretion as also higher false negative results. ${ }^{[1]}$

van der Walt (5) emphasizes the 'role' of pathologists in the identification of the excised tissue to be parathyroid and to determine whether it is hyperplasia or neoplasm. With the advances made in molecular and genetic tests, a few markers are emerging which may help us to differentiate 
carcinomas. Frozen section (FS) can be supplemented by IOPTH and intra-operative radioguidance with miniature gamma probe. Also the latest techniques used including ultrasonography with high frequency probes and selective parathyroid venous sampling are slowly removing the need for intra-operative frozen section. ${ }^{[5]}$ Farrag ${ }^{[6]}$ et al recommend the use of point-of-care IOPTH assay of needle aspirates as an alternative to FS. This was further validated by Coan ${ }^{[7]}$ et al who found that an aspirate IOPTH which was $>1.5$ times more than the baseline serum IOPTH was associated with $100 \%$ specificity without any false positivity.

Iacobone ${ }^{[8]}$ et al studied 102 patients who underwent parathyroidectomies and performed both frozen section (FS) and IOPTH on them. They concluded that it was difficult for the pathologists to distinguish between adenoma and hyperplasia and the onus lies on the surgeon regarding the same. Diagnostic dilemmas were multifactorial including FS artifact, follicular patterned growth, oncocytic thyroid nodules and even brown fat. ${ }^{[8]}$ We encountered one case of oxyphilic variant of parathyroid adenoma, which on imprint smears and frozen section showed sheets of oncocytic cells. However, prior history and elevated preoperative PTH levels helped us in the diagnosis on FS. The only disadvantages of IOPTH they found was cost restrictions and accuracy in multiglandular disease. Both these can be overcome as they found that IOPTH was more cost-effective than FS in patients with brown fat, lymph nodes or scar and when 50\% cut-off rule was used, multiglandular involvement can be predicted with $100 \%$ accuracy. ${ }^{[8]}$

In our set-up, surgeons usually prefer to do frozen section especially when the gland is small. IOPTH is not used by all operating surgeons to determine the success of surgery. In our small group, we found that IOPTH was sensitive. For example, if it were considered in case 1, the surgeon should have been alerted as the IOPTH did not drop. Hence, we found FS to be useful only in 2 cases of multiple nodules in the neck, aiding the surgeon to identify the correct nodule of involved parathyroid.

Thus, Osamura and Hunt ${ }^{[9]}$ laid out certain criteria for performing FS:

i. IOPTH is unavailable. They further recommend to keep fresh tissue available, till the results of IOPTH are available. FS to be performed if there is no significant drop in the PTH levels.

ii. Presence of very small fragments

iii. When intrathymic parathyroid is suspected iv. Parathyroids with clinical or histologic atypical features. Though diagnosis of carcinoma is not essential on FS, but if the clinician is alerted about the possibility of malignancy, then en-bloc resection of the gland can be done. Also, autotransplantation of the affected gland should be avoided in case of PHP.

Dewan et al ${ }^{[10]}$ conclude that FS was an unnecessary tool in the kit of an experienced parathyroid surgeon. Preoperative scans, intraoperative gross examination and maybe IOPTH could well replace a pathologist's intraoperative consultation.

Limitations of the study include a small sample size. We wanted to follow the model of Tampi et al ${ }^{[11]}$ who tried on a small sample to note its feasibility in our setup. This can be taken as a pilot study to be followed by another one with larger sample size and statistical analysis before concluding the utility or futility of intraoperative frozen section in parathyroid surgery.

\section{Conclusion}

Frozen section during parathyroid surgery is indicated in very few conditions. IOPTH and further ex-vivo aspirate IOPTH can be used to determine the success of surgery. Frozen section may be used only to confirm parathyroid tissue, when the surgeon is doubtful, in cases of ectopic location, intrathymic tumor and when malignancy is suspected.

\section{Acknowledgement}

We would like to acknowledge the help of our technical staff of Department of Pathology and Biochemistry, KMC, Manipal, for all their support.

\section{References:}

1. Mehta NY, Ruda JM, Kapadia S, Boyer PJ, Hollenbeak CS, Stack BC. Relationship of Technetium Tc 99m Sestamibi Scans to Histopathological Features of Hyperfunctioning Parathyroid Tissue. Arch Otolaryngol Head Neck Surg. 2005;131:493-8.

2. Guarda LA. Rapid intraoperative parathyroid hormone testing with surgical pathology correlations: the "chemical frozen section". Am J Clin Pathol. 2004;122:704-12.

3. Agarwal G, Barraclough BH, Reeve TS, Delbridge LW. Minimally invasive parathyroidectomy using the "focused" lateral approach. II. Surgical technique. ANZ J Surg. 2002;72:147-51

4. Khalid AN, Hollenbeak CS, Higginbotham BW and Stack BC. Accuracy and definitive interpretation of preoperative technetium $99 \mathrm{~m}$ sestamibi imaging based on the discipline of the reader. Head Neck. 2009;31:576-82.

5. Van der Walt J. Pathology of the parathyroid glands. Diagn Histopathol. 2012;18:221-33. 
6. Farrag T, Weinberger P, Seybt M, Terris DJ. Point-of-care rapid intraoperative parathyroid hormone assay of needle aspirates from parathyroid tissue: a substitute for frozen sections. Am J Otolaryngol 2011;32:574-7.

7. Coan KE, Yen TWF, Carr AA, Bullock M, Colon-Franco $\mathrm{JM}$, Evans DB,et al. Intraoperative ex vivo parathyroid aspiration: A point-of-care test to confirm parathyroid tissue. Surgery. 2016;160(4):850-7.

8. Iacobone M, Scarpa M, Lumachi F, Favia G (2005) Are frozen sections useful and cost-effective in the era of intraoperative qPTH assays? Surgery 138:1159-1164.

9. Osamura RY and Hunt JL. Virchows Arch 2008;453:433-40.

10. Dewan AK, Kapadia SB, Hollenbeak CS, Stack BC Jr. Is routine frozen section necessary for parathyroid surgery? Otolaryngol 2005;133:857-62.

11. Tampi $\mathrm{C}$, Chavan $\mathrm{N}$ and Parikh D. Intraoperative parathyroid hormone assay-cutting the Gordian knot - Indian J Endocrinol Metab. 2014 Mar-Apr; 18(2): 210-212.

*Corresponding author:

Dr. Padmapriya Jaiprakash, Department of Pathology, Basic Sciences Block, Kasturba Medical College, Manipal Academy of Higher Education, Madhava Nagar, Manipal - 576104, KARNATAKA, INDIA.

Email: padmapriya.j@gmail.com

Financial or other Competing Interests: None. 